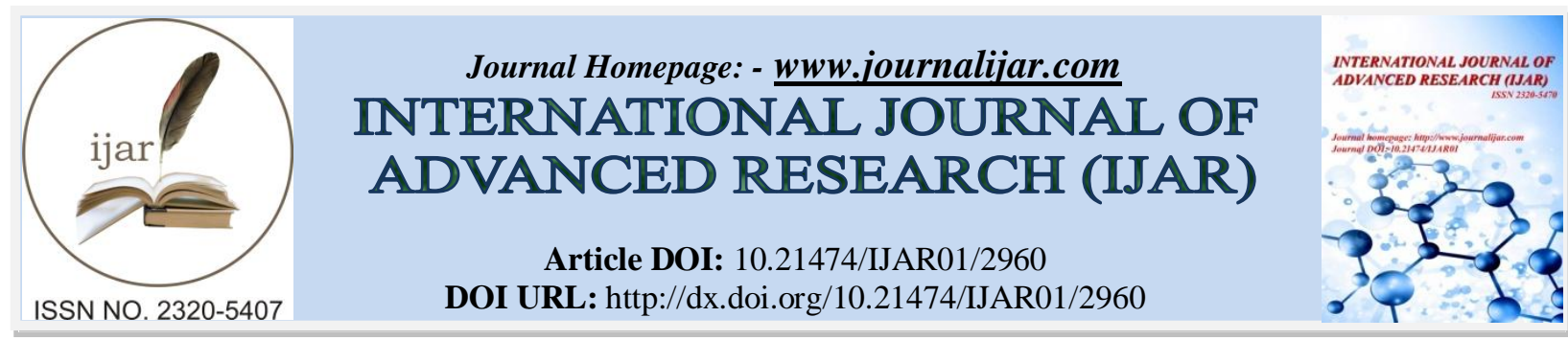

RESEARCH ARTICLE

\title{
COMPARATIVE STUDY BETWEEN SUCCINYLATED GELATIN (GELOFUSINE) VERSUS RINGER'S ACETATE REGARDING SAFETY AND EFFICACY IN ADULT PATIENTS UNDERGOING CARDIAC SURGERY.
}

\begin{abstract}
Mahdy Ahmed Abdelhady ${ }^{1}$, M.Sc., Mostafa Mohammed Elsaid Elhamamssy ${ }^{1}$,MD, Samar Samir Ali ${ }^{2}$, MD, Hoda Hafez Bahi Eldin ${ }^{2}$, MD, Hany Mahmoud Yassin Moussa ${ }^{1}$, MD and Mohammed Ahmed Hamed ${ }^{1}$, MD. 1. Anesthesiology Department Faculty of medicine, Al Fayoum University, Egypt.

2. Anesthesiology Department National heart institute (NHI), Cairo, Egypt.
\end{abstract}

\section{Manuscript Info}

(........................

Manuscript History

Received: 29 November 2016

Final Accepted: 26 December 2016

Published: January 2017

\section{Abstract}

In this prospective, randomized, double-blinded study 60 adult patients underwent cardiac surgery with CPB were randomly assigned to receive either succinylated gelatin or Ringer's acetate as priming and perioperative maintenance. We found that the dose of the study solution was significantly less in gelofusine group. The $\mathrm{pH}$ level, the $\mathrm{BE}$ values, coagulation parameters and hematological parameters showed significant changes in the gelatin group. We concluded that: Succinylated gelatin is more effective plasma expander than Ringer's acetate but with worse outcome regarding the acid base balance and coagulation parameters.

Copy Right, IJAR, 2016,. All rights reserved.

\section{Introduction:-}

Within the human body, fluid homeostasis is a result of complex interactions between different compartments and barriers and the prerequisite of hemodynamic stability. ${ }^{(1)}$ Severe intravascular hypovolemia results in a decreased cardiac output, tissue hypoperfusion and organ dysfunction. ${ }^{(2,3)}$ Therefore, perioperative fluid management should avoid these complications via replacing blood and fluid losses as adequately as possible. However, debates regarding the adequate type, amount and composition of fluids are ongoing. ${ }^{(2,4,5)}$ Colloids are often added to solutions used for volume replacement to keep a colloidal osmotic pressure in the intravascular compartment, ${ }^{(6)}$ they are now recommended as an alternative to crystalloids in several resuscitation guidelines ${ }^{(7)}$, but still controversially discussed. ${ }^{(8)}$ Colloids can be classified into natural (e.g. albumin) and synthetic colloids (e.g. dextran, hydroxyethyl starch (HES) or succinylated gelatin) ${ }^{(6)}$. Colloids have a smaller volume of distribution than crystalloids; therefore, fewer amounts of fluid are needed to restore intravascular volume, ${ }^{(9)}$ they also have been shown to improve oxygen transport, tissue oxygenation, and cardiac output. ${ }^{(10)}$ Colloids have been used after cardiac surgery due to their ability to maintain intravascular volume and regional tissue perfusion more efficiently than crystalloids, (11-12) however all intravenous fluids produce dilutional coagulopathy and colloids interact with the coagulation System ${ }^{(13)}$. Gelatins can impair coagulation ${ }^{(14)}$ and affect platelet aggregation. ${ }^{(15)}$ On the other hand, Ringer's solution does not disturb coagulation ${ }^{(16)}$ and can be used for fluid therapy in patients with coagulation disorders. No differences in mortality among critically ill patients had been demonstrated after the use of different colloids or crystalloids. (17) Cardiopulmonary bypass (CPB) causes a strong activation of the haemostatic system with increasing the risk of postoperative bleeding. ${ }^{(18)}$ Previously, Wilkes and colleagues ${ }^{(19)}$ showed that the use of HES solutions (HES 450/0.7 and HES 200/0.5) after CPB predisposed patients to increased blood loss. Results of many studies support an evidence-based recommendation for the avoidance or cautious use of HES solutions in patients undergoing surgery with CPB. ${ }^{(20)}$ Studies showed that, chloride containing solutions produce hyperchloremia proportional to 
their chloride content which persists for at least 6 hours. ${ }^{(21)}$ The use of newer preparations of balanced colloids results in less impairment of acid base status and is considered to be a promising strategy to avoid metabolic acidosis associated with colloids suspended in $0.9 \%$ saline. ${ }^{(22)}$ Hyperchloremia is evident to suppress renin activity in humans. ${ }^{(21)}$.

\section{Patient \& Methods:-}

After the approval of the institutional review board and the Ethics Committee of Al Fayoum University, written informed consent from 60 patients scheduled for cardiac surgery were obtained.

\section{Inclusion criteria:-}

Male and female adult patients age from 20 to 55 years old underwent elective cardiac surgery with cardiopulmonary bypass with an expected time of CPB between 30 minutes and 3.5 hours. Exclusion criteria; included a history of cardiac surgery, severe congestive heart failure (ejection fraction $\leq 25 \%$ ), hemoglobin concentration $\leq 10 \mathrm{~g} / \mathrm{dL}$ before study, a known allergy to gelatins, renal insufficiency (serum creatinine of $\geq 2.5$ $\mathrm{mg} / \mathrm{dL}$ ), significant hepatic disease (liver function tests $\geq 3$ red upper limit of normal), or a history of coagulation disorders.

This study included two groups: Group A: 30 adult patients - age from 20 to 55 years old - who received Ringer's acetate solution. Group B: 30 adult patients- age from 20 to 55 years old - who received modified gelatin solution. Preoperative cardiac medications were continued until the morning of surgery, except for angiotensin-converting enzyme inhibitors and angiotensin II antagonists were discontinued at morning of surgery. Acetylsalicylic acid was discontinued 5 days before surgery.

\section{Anesthesia:-}

All patients were pre-medicated with IV. midazolam $(0.1 \mathrm{mg} / \mathrm{kg})$, Anesthesia was induced with propofol (1.0-1.5 $\mathrm{mg} / \mathrm{kg}$ ), fentanyl (3-10 $\mu \mathrm{g} / \mathrm{kg})$, and pancuronium bromide $(0.1 \mathrm{mg} / \mathrm{kg})$, Then Patients were intubated with an oral endotracheal tube and ventilated with a minute volume of $80-100 \mathrm{ml} / \mathrm{kg} / \mathrm{min}$. to achieve a target alveolar partial carbon dioxide pressure between 35 and $40 \mathrm{mmHg}$. Arterial cannula and central venous line were inserted. Heart rate, ECG, invasive arterial blood pressure, central venous pressure and nasopharyngeal temperature were continuously measured. A bladder catheter was inserted to monitor urine output during and after the operation. Anesthesia was maintained with isoflurane 0.5-1.5 MAC till cardiopulmonary bypass, then maintained with propofol (50-100 $\mu \mathrm{g} / \mathrm{kg} / \mathrm{min})$, incremental doses- if needed-of fentanyl \& pancuronium during CPB.

\section{Anticoagulation and Cardiopulmonary Bypass:-}

Anticoagulation was established, while the aortic purse-string sutures are placed before cannulation, with an initial bolus 300-400 IU/kg BW of heparin sodium to get activated clotting time (ACT) higher than $480 \mathrm{sec}$. Additional heparin - if needed - was administrated to maintain ACT higher than $480 \mathrm{sec}$ during the whole procedure. The cardiopulmonary bypass circuit was prepared as following:

- For group A: $1,500 \mathrm{~mL}$ of Ringer's acetate $+0.5 \mathrm{~g} / \mathrm{kg}$ mannitol.

- For group B: $1000 \mathrm{~mL}$ of gelofusine solution $+500 \mathrm{ml}$ Ringer's acetate $+0.5 \mathrm{~g} / \mathrm{kg}$ mannitol.

After anticoagulation with heparin (300 IU/kg), cardiopulmonary bypass was performed using a non-pulsatile blood flow at $2.5 \mathrm{~L} / \mathrm{min} / \mathrm{m} 2$, a non-heparin-coated circuit, and a membrane oxygenator (Quadrox, Maquet, Hirrlingen, Germany; Dideco Compactflow, Mirandola, Italy; or Hilite 7000, Medos, Stollberg, Germany). Mild-to-moderate hypothermia was induced $\left(28^{\circ}-32^{\circ} \mathrm{C}\right)$ and norepinephrine was given to maintain a mean arterial pressure $\geq 60$ mmHg. St Thomas crystalloid cardioplegic solution (Hamburg) was used for myocardial preservation. Randomization was performed using envelop method. The anesthetist, who collected the data, was blinded with the study solutions. Fluid infusion was adjusted individually for each patient to achieve hemodynamic stability, which is defined as a systolic blood pressure $>90 \mathrm{mmHg}$ and avoidance of decrease of systolic blood pressure $>20 \%$ from baseline, a heart rate $<100$ beats $/ \mathrm{min}$ and avoidance of an increase in heart rate of $30 \%$ from baseline, normal central venous pressure $5-12 \mathrm{mmHg}$ and urine output $>0.5 \mathrm{~mL} / \mathrm{kg} / \mathrm{h}$, using a maximum study solution dose of $50 \mathrm{ml} / \mathrm{kg}$. If additional volume was needed Ringer acetate solution was given. The use of sodium bicarbonate was only allowed if arterial $\mathrm{pH}$ was $<7.2$. Regarding concomitant medication, the use of synthetic colloids other than the study solution was forbidden until end of surgery. Transfusion triggers for the transfusion of allogeneic red blood cells were hemoglobin concentrations of $\leq 7.0 \mathrm{~g} / \mathrm{dL}$ (during cardiopulmonary bypass), 7.5 to $8.0 \mathrm{~g} / \mathrm{dL}$ after weaning from cardiopulmonary bypass, and 8.0 to $8.5 \mathrm{~g} / \mathrm{dL}$ after the end of surgery. Before weaning from CPB all patients were 
rewarmed to 37c (nasopharyngeal temperature) \& heparin was neutralized with 1:1 protamine sulphate to regain normal ACT.

\section{Measured parameters:-}

The primary variable for assessing therapeutic equivalence was the volume of the study solution in milliliters needed for hemodynamic stabilization until 1 hour after the end of surgery (i.e., the cumulative volume of the study solution in milliliters administered up to this time point). Therapeutic equivalence regarding the primary variable was defined as the treatment difference $\leq 500 \mathrm{~mL}$ in the amount of the study solution. Consecutive variables analyzed were arterial $\mathrm{pH} \&$ base excess at the end of surgery. Arterial $\mathrm{pH}$ was measured at each time point from the induction of anesthesia to 1 hour after arrival in the intensive care unit (ICU) (including: room air, after induction, on bypass, before weaning from bypass, after bypass is off, before end of surgery, and after arrival to the ICU samples). In addition, base excess values were measured at the same time points as arterial $\mathrm{pH}$. All blood gas analysis samples were measured at $37^{\circ} \mathrm{C}$. Secondary parameters were hemodynamic parameters, fluid balance, and concomitant vasoactive medications. Safety parameters were coagulation variables (platelet count, prothrombin time, prothrombin concentration, and INR), hematology parameters (hemoglobin and hematocrit) clinical chemistry parameters (creatinine, urea, AST and ALT), serum electrolytes (Na \& K), and adverse events, safety parameters were measured preoperative as a baseline $\&$ one hour after end of surgery.

\section{Statistical Analysis:-}

Data was collected and coded to facilitate data manipulation and double entered into Microsoft Access and data analysis was performed using SPSS software version 18 under windows 7. Simple descriptive analysis in the form of numbers and percentages for qualitative data, and arithmetic means as central tendency measurement, standard deviations as measure of dispersion for quantitative parametric data, and inferential statistic test: For quantitative parametric data: In-depended student t-Test used to compare measures of two independent groups of quantitative data. Paired t-test used in comparing two dependent quantitative data. For quantitative non parametric data: Non Paired variables; Mann-Whitney test used in comparing two independent groups. Paired variables; Wilcoxon test used in comparing two groups of dependant data. For qualitative data: Chi square test to compare two of more than two qualitative groups. The level $\boldsymbol{P} \leq \mathbf{0 . 0 5}$ was considered the cut-off value for significance. The sample size was calculated according to Epi Info 2000. Using a special formula based on the lowest reported values of different study outcomes; at a confidence interval of 95\%, alpha error 0.05 , beta error 0.1 and $90 \%$ power of study.

\section{Results:-}

The demographic data, type of surgery and the operative details showed no significant difference between the two groups (table 1), (table 2) and table (3).

Table 1:- Comparisons of age, and weight in different study groups

\begin{tabular}{|l|c|c|c|c|c|c|}
\hline \multirow{2}{*}{ Variables } & \multicolumn{2}{|c|}{$\begin{array}{c}\text { Group A } \\
(\mathrm{n}=30)\end{array}$} & \multicolumn{2}{c|}{$\begin{array}{c}\text { Group B } \\
(\mathrm{n}=30)\end{array}$} & \multirow{2}{*}{ p-value. } & \\
\cline { 2 - 5 } & Mean & SD & Mean & SD & & \\
\hline Age (years) & 41.6 & 9.7 & 43.3 & 9.4 & 0.5 & NS \\
\hline Weight (kg) & 76.1 & 8.6 & 74.7 & 9.4 & 0.5 & NS \\
\hline
\end{tabular}

$\mathrm{NS}=$ no statistically significant difference. Group A = Ringer's acetate, Group B = succinylated gelatin

Table 2:- Comparisons of gender and type of operation in different study groups:

\begin{tabular}{|c|c|c|c|c|c|c|}
\hline \multirow[t]{2}{*}{ Variables } & \multicolumn{2}{|c|}{$\begin{array}{c}\text { Group A } \\
(\mathrm{n}=30)\end{array}$} & \multicolumn{2}{|c|}{$\begin{array}{c}\text { Group B } \\
(\mathrm{n}=30)\end{array}$} & \multirow[t]{2}{*}{ p-value } & \multirow[t]{2}{*}{ Sig. } \\
\hline & No. & $\%$ & No. & $\%$ & & \\
\hline \multicolumn{7}{|l|}{ Sex } \\
\hline Male & 20 & $66.7 \%$ & 15 & $50 \%$ & \multirow[t]{2}{*}{0.3} & \multirow[t]{2}{*}{$\mathrm{NS}$} \\
\hline Female & 10 & $33.3 \%$ & 15 & $50 \%$ & & \\
\hline \multicolumn{7}{|l|}{ Type of operation } \\
\hline Valvular & 20 & $66.7 \%$ & 16 & $53.3 \%$ & \multirow[t]{2}{*}{0.4} & \multirow[t]{2}{*}{$\mathrm{NS}$} \\
\hline CABAG & 10 & $33.3 \%$ & 14 & $46.7 \%$ & & \\
\hline
\end{tabular}


Table 3:- Comparisons of operation data in different study groups:

\begin{tabular}{|l|c|c|c|c|c|c|}
\hline \multirow{2}{*}{ Variables } & \multicolumn{2}{|c|}{$\begin{array}{c}\text { Group A } \\
(\mathrm{n}=30)\end{array}$} & \multicolumn{2}{c|}{$\begin{array}{c}\text { Group B } \\
(\mathrm{n}=30)\end{array}$} & \multirow{2}{*}{ p-value } \\
\cline { 2 - 7 } & Mean & SD & Mean & SD & & \\
\hline EF\% & 68.3 & 5.3 & 67.4 & 5.6 & 0.6 & NS \\
\hline Duration of surgery (hrs) & 5 & 0.41 & 5.1 & 0.47 & 0.9 & NS \\
\hline $\begin{array}{l}\text { Cardiopulmonary bypass time } \\
\text { (min) }\end{array}$ & 110.2 & 22.8 & 107.4 & 17.8 & 0.6 & NS \\
\hline Cross clamp time (min) & 74.4 & 11.7 & 73.5 & 13.5 & 0.8 & NS \\
\hline
\end{tabular}

The dose of the study solution was highly significant between the two groups (in group A -Ringer's acetate-: $3700 \pm$ $427.5 \mathrm{ml}$ in group B -gelofusine group-: $2365.3 \pm 100.8$ with $\mathrm{p}$ value $\mathbf{< 0 . 0 0 1})$. It is noted that there was no need for additional solution in group B (gelofusine group), on the other hand in group A (Ringer's acetate) almost all cases needed additional solution $(453.3 \pm 366.9 \mathrm{ml}$.). Also the total amount of solution needed was highly significant between the two groups (in group A: $4153.3 \pm 330.3$, in group B $2365.3 \pm 100.8$ with p value $<\mathbf{0 . 0 0 1}$ ) as shown in table (4)

Table 4:- Comparisons of volume of study solutions in different study groups:

\begin{tabular}{|l|c|c|c|c|c|c|}
\hline \multirow{2}{*}{ Variables } & \multicolumn{2}{|c|}{$\begin{array}{c}\text { Group A } \\
(\mathrm{n}=30)\end{array}$} & \multicolumn{2}{c|}{$\begin{array}{c}\text { Group B } \\
(\mathrm{n}=30)\end{array}$} & p-value \\
& Mean & SD & Mean & SD & \\
\hline Dose of study solution & 3700 & 427.5 & 2365.3 & 100.8 & $<0.001$ & HS \\
\hline Additional solution used & 453.3 & 366.9 & 0 & 0 & $<0.001$ & HS \\
\hline Total amount & 4153.3 & 330.3 & 2365.3 & 100.8 & $<0.001$ & HS \\
\hline
\end{tabular}

HS = highly significant difference.

Regarding the PH levels, there was no significant difference between the two groups at T1 (Room air; baseline) and T2 (After induction). On the other hand from T3 to the end point of the current study there was an obvious reduction in the $\mathrm{PH}$ level of group $\mathrm{B}(4 \%$ succinylated gelatin), which was statistically highly significant in comparison of group A (Ringer's acetate). Figure (1) shows the time line course of the PH in different groups.

The BE also found no significant difference between the two groups at T1 and T2. On the other hand from T3 to the end point of the study, the BE values showed a highly significant difference between the two groups. In group B (4\% succinylated gelatin) the BE values decreased and became at the negative side in contrast to the group A (Ringer's acetate). Figure (2) illustrates the time line course of the BE throughout the study in both groups.

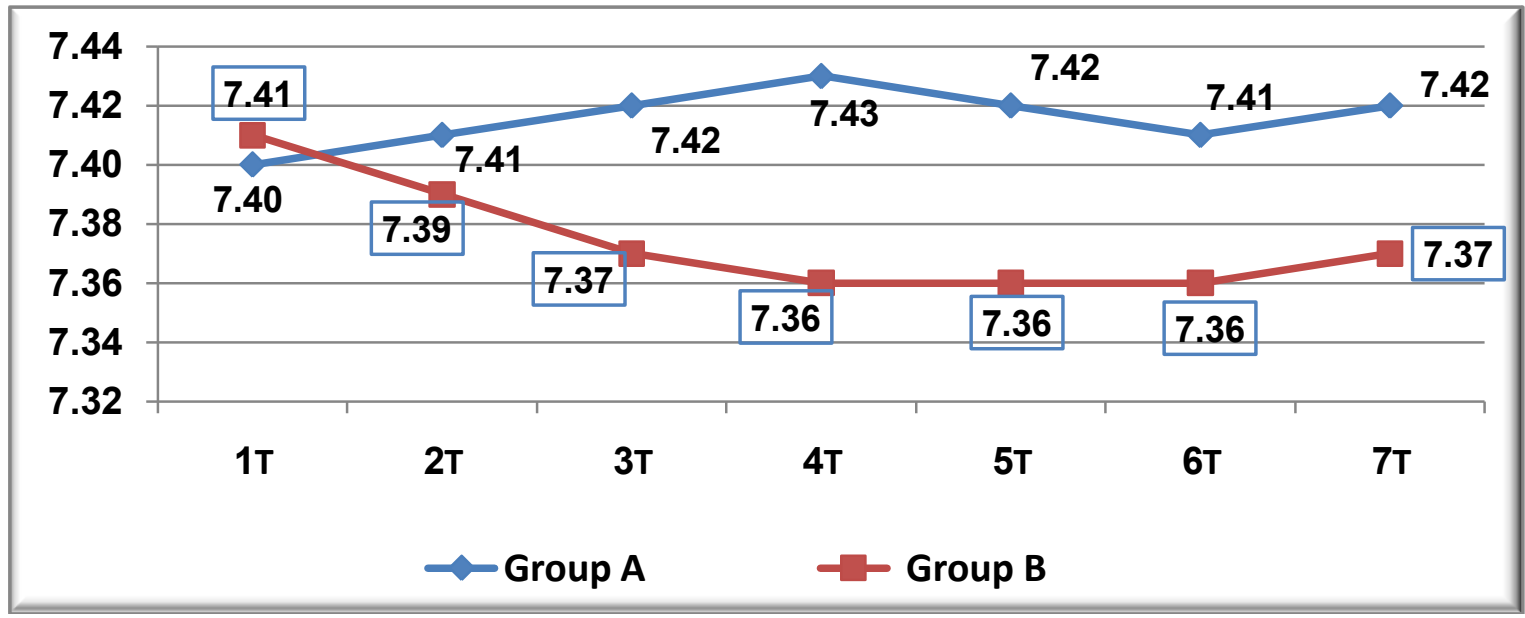

Figure 1:- time line course of $\mathrm{PH}$ in different groups

T1 = Room air, T2 (After induction) T3 (on bypass) T4 (before weaning) T5 (after bypass) T6 (end of surgery) T7 (at ICU) 


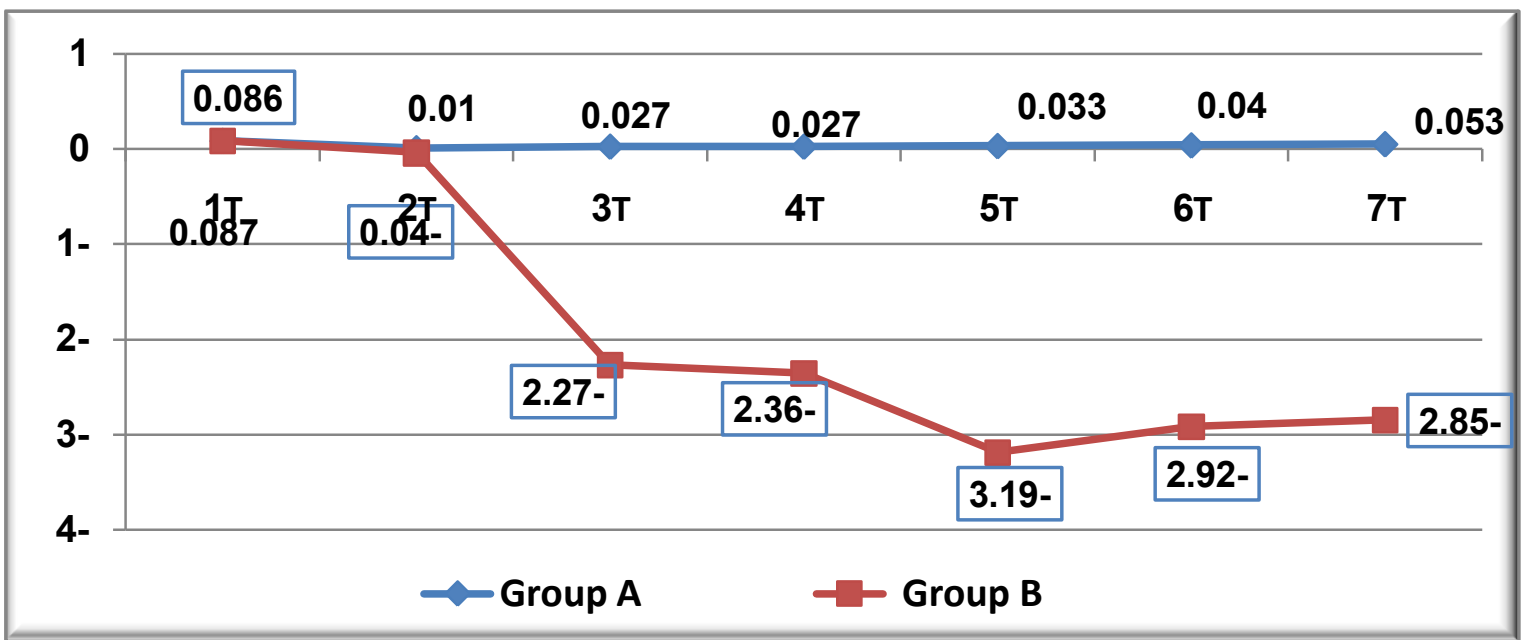

Figure 2:- time line course of BE

Apart from the CVP, the secondary variables showed no significance between the two groups as shown in tables (5) $\&(6)$

Table 5:- Comparisons of secondary variables at end of surgery in different study groups:

\begin{tabular}{|l|c|c|c|c|c|c|}
\hline \multirow{2}{*}{ Variables } & \multicolumn{2}{|c|}{$\begin{array}{c}\text { Group A } \\
(\mathrm{n}=30)\end{array}$} & \multicolumn{2}{c|}{$\begin{array}{c}\text { Group B } \\
(\mathrm{n}=30)\end{array}$} & \multirow{2}{*}{ p-value } \\
\cline { 2 - 6 } & Median & IQR & Median & IQR & & \\
\hline Hear rate & 90 & $5(85-90)$ & 90 & $10(80-90)$ & 0.06 & NS \\
\hline CVP & 6 & $1(5-6)$ & $\mathbf{7}$ & $3(6-9)$ & $\mathbf{0 . 0 0 1}$ & HS \\
\hline
\end{tabular}

Table 6:- Comparisons of secondary variables at end of surgery in different study groups:

\begin{tabular}{|l|l|l|l|l|l|l|}
\hline \multirow{2}{*}{ Variables } & \multicolumn{2}{|l|}{$\begin{array}{l}\text { Group A } \\
(\mathrm{n}=30)\end{array}$} & \multicolumn{2}{l}{$\begin{array}{l}\text { Group B } \\
(\mathrm{n}=30)\end{array}$} & \multirow{2}{*}{ Sig. } \\
\cline { 2 - 6 } & Mean & SD & Mean & SD & & \\
\hline Systolic blood pressure & 120.2 & 7.7 & 119.3 & 7.8 & 0.7 & NS \\
\hline UOP & 2.5 & 0.76 & 2.4 & 0.84 & 0.8 & NS \\
\hline Vasoactive drugs & 0.47 & 0.7 & 0.37 & 0.6 & 0.6 & NS \\
\hline
\end{tabular}

All safety variables including; platelet count, prothrombin time, prothrombin concentration, INR, hemoglobin, hematocrit, kidney function, liver function and serum electrolytes, showed no significant difference between the two groups when compared preoperatively, however, when comparing the safety parameters within the same group, we showed that; in group A (Ringer's acetate) (table 7) platelet count has significantly decreased after operation (226.9 \pm 25.8 to $171.4 \pm 18.4 \mathrm{p}$-value $<0.001)$, the prothrombin time prolonged and concentration decreased, the INR showed a significant increase after operation (with1.1 \pm 0.06 preoperative vs. $1.2 \pm 0.04$ postoperative $\mathrm{p}$-value 0.02 ). Also, the hematological parameters; hemoglobin and hematocrit decreased significantly. Apart from the (AST), no statistical significances were recorded regarding the clinical chemistry parameters and postoperative serum potassium level significantly increased.

Table 7:- Comparisons of safety variables before and after operation among group A:

\begin{tabular}{|c|c|c|c|c|c|c|}
\hline \multirow[t]{2}{*}{ Variables } & \multicolumn{2}{|c|}{ Before operation } & \multicolumn{2}{|c|}{ After operation } & \multirow[t]{2}{*}{ p-value } & \multirow[t]{2}{*}{ Sig. } \\
\hline & Mean & SD & Mean & SD & & \\
\hline \multicolumn{7}{|l|}{ Coagulation profile } \\
\hline Platelet count & 226.9 & 25.8 & 171.4 & 18.4 & $<0.001$ & HS \\
\hline Prothrombin time & 13 & 0.42 & 13.8 & 0.38 & 0.002 & HS \\
\hline Prothrombin concentration & 91.7 & 3 & 87.3 & 2.4 & 0.004 & HS \\
\hline INR & 1.1 & 0.06 & 1.2 & 0.04 & 0.02 & $\mathbf{S}$ \\
\hline \multicolumn{7}{|l|}{ Hematological parameters } \\
\hline Hemoglobin & 12.7 & 0.94 & 10.7 & 0.61 & $<0.001$ & HS \\
\hline HCT & 37.9 & 2.9 & 32.3 & 1.8 & $<0.001$ & HS \\
\hline
\end{tabular}




\begin{tabular}{|c|c|c|c|c|c|c|}
\hline \multicolumn{7}{|c|}{ Clinical chemistry parameters } \\
\hline Creatinine & 0.97 & 0.12 & 0.99 & 0.13 & 0.1 & NS \\
\hline Urea & 30.8 & 7 & 31 & 6.9 & 0.06 & NS \\
\hline AST & 17.5 & 5.3 & 27.6 & 5.6 & $<0.001$ & HS \\
\hline ALT & 15.4 & 2.8 & 15.5 & 3 & 0.4 & NS \\
\hline \multicolumn{7}{|c|}{ Serum electrolytes } \\
\hline $\mathrm{Na}$ level & 139.3 & 3.5 & 139.8 & 3.2 & 0.2 & NS \\
\hline K level & 3.9 & 0.28 & 4.1 & 0.28 & $<0.001$ & HS \\
\hline
\end{tabular}

Also, the safety variables within group B (gelofusine group) showed similar changes as occurred in group A, except that there was no significance regarding the potassium level postoperatively as shown in table (8).

Table 8:- (continued) Comparisons of safety variables before and after operation among group B:

\begin{tabular}{|c|c|c|c|c|c|c|}
\hline \multirow[t]{2}{*}{ Variables } & \multicolumn{2}{|c|}{ Before operation } & \multicolumn{2}{|c|}{ After operation } & \multirow[t]{2}{*}{ p-value } & \multirow[t]{2}{*}{ Sig. } \\
\hline & Mean & SD & Mean & SD & & \\
\hline \multicolumn{7}{|l|}{ Coagulation profile } \\
\hline Platelet count & 221.8 & 23.9 & 149 & 15.7 & $<0.001$ & HS \\
\hline Prothrombin time & 13.1 & 0.41 & 15.2 & 0.46 & $<0.001$ & HS \\
\hline $\begin{array}{l}\text { Prothrombin } \\
\text { concentration }\end{array}$ & 91.9 & 2.9 & 79.2 & 2.4 & $<0.001$ & HS \\
\hline INR & 1.1 & 0.04 & 1.3 & 0.05 & $<0.001$ & HS \\
\hline \multicolumn{7}{|c|}{ Hematological parameters } \\
\hline Hemoglobin & 12.7 & 0.9 & 9.5 & 0.5 & $<0.001$ & HS \\
\hline HCT & 38.2 & 2.9 & 28.4 & 1.6 & $<0.001$ & HS \\
\hline \multicolumn{7}{|c|}{ Clinical chemistry parameters } \\
\hline Creatinine & 0.99 & 0.14 & 0.99 & 0.13 & & \\
\hline Urea & 32 & 7.1 & 32 & 7.1 & & \\
\hline AST & 17.7 & 5.2 & 27.7 & 5.1 & $<0.001$ & HS \\
\hline ALT & 18.1 & 11.2 & 18.1 & 11.2 & & \\
\hline \multicolumn{7}{|l|}{ Serum electrolytes } \\
\hline $\mathrm{Na}$ level & 139.9 & 3.2 & 139.8 & 3.1 & 0.7 & NS \\
\hline K level & 3.9 & 0.26 & 3.9 & 0.25 & 0.9 & NS \\
\hline
\end{tabular}

To find out the differences between the two groups, we compared the postoperative values of both groups (table 9). It was found that, no significant differences between the two groups regarding the clinical chemistry parameters or serum electrolytes. However, there were; significant decrease in postoperative platelet count, significant prolongation in prothrombin time, significant decrease in postoperative prothrombin concentration and significant increase in INR in group B(gelofusine group) when compared to group A (Ringer's acetate). Also, there was a significant decrease in hemoglobin concentration and hematocrit in succinylated gelatin group when compared to Ringer's acetate.

Table 9:- Comparisons of safety variables after operation in different study groups:

\begin{tabular}{|c|c|c|c|c|c|c|}
\hline \multirow[t]{2}{*}{ Variables } & \multicolumn{2}{|c|}{$\begin{array}{c}\text { Group A } \\
(\mathrm{n}=30)\end{array}$} & \multicolumn{2}{|c|}{$\begin{array}{c}\text { Group B } \\
(\mathrm{n}=30)\end{array}$} & \multirow[t]{2}{*}{ p-value } & \multirow[t]{2}{*}{ Sig. } \\
\hline & Mean & SD & Mean & SD & & \\
\hline \multicolumn{7}{|l|}{ Coagulation profile } \\
\hline Platelet count & 171.4 & 18.4 & 149.9 & 15.7 & $<0.001$ & HS \\
\hline prothrombin time & 13.7 & 0.38 & 15.2 & 0.46 & $<0.001$ & HS \\
\hline prothrombin concentration & 87.3 & 2.4 & 79.2 & 2.4 & $<0.001$ & HS \\
\hline INR & 1.2 & 0.04 & 1.3 & 0.05 & $<0.001$ & HS \\
\hline \multicolumn{7}{|l|}{ Hematological parameters } \\
\hline Hemoglobin & 10.7 & 0.61 & 9.5 & 0.52 & $<0.001$ & HS \\
\hline HCT & 32.3 & 1.8 & 28.4 & 1.6 & $<0.001$ & HS \\
\hline
\end{tabular}




\begin{tabular}{|l|c|c|c|c|c|c|}
\hline Creatinine & 0.99 & 0.14 & 0.99 & 0.14 & 0.9 & NS \\
\hline Urea & 31.5 & 6.9 & 32 & 7.1 & 0.8 & NS \\
\hline AST & 27.6 & 5.6 & 27.7 & 5.1 & 0.9 & NS \\
\hline ALT & 18.1 & 11.1 & 18 & 11.2 & 0.9 & NS \\
\hline Serum electrolytes & 139.7 & 3.2 & 139.8 & 3.2 & 0.9 & NS \\
\hline Na level & 4.1 & 0.28 & 3.9 & 0.25 & 0.08 & NS \\
\hline K level
\end{tabular}

\section{Discussion:-}

One of the major findings in our study was the primary variable for assessing the therapeutic equivalence defined as the volume of the study solution in milliliters (including the priming); the current study denoted that gelofusine is superior to Ringer's acetate in maintaining hemodynamic stabilization with much less volume. This is met with several studies which denoted that colloids are more effective regarding their plasma expanding property than crystalloids. ${ }^{(9,21)}$ Regarding $4 \%$ succinylated gelatin (the colloid of use in this study), and being a colloid of low average molecular weight, there was a believe that it escapes the capillary pores faster than that of medium and high molecular weight can do, hence, less plasma expanding effect ${ }^{(23)}$, however several studies have described gelatins and starches as equal plasma expanders both in: animal models ${ }^{(24-26)}$ and human. ${ }^{(20,27)}$ Moreover, in their study, Dileep et al. ${ }^{(21)}$ have described an equal duration of plasma expansion of both $4 \%$ succinylated gelatin (gelofusine) and 6\% hydroxyethyl starch (Voluven) attributing this to the fact that hydroxyethyl starch is eliminated by the cleavage action of the serum amylase, which increased four times after infusion of hydroxyethyl starch as reported by Wilkes et al. ${ }^{(28)}$

The $\mathrm{PaCO} 2$ levels in this study were maintained by ventilation therefore, base excess (BE) and PH changes reflected any change in the non-respiratory (i.e. metabolic) state. Regarding the $\mathrm{pH}$ levels, there was a significant difference between the two groups from T3 to the end point of the current study. Ten cases of group B (4\% succinylated gelatin) reached a PH level less than 7.35 to a maximum fall to 7.31(i.e. metabolic acidosis). This can be attributed to the fact that gelofusine is a saline - based gelatin, it contains: $145 \mathrm{mmol} / \mathrm{l}$ sodium ion concentration, $120 \mathrm{mmol} / \mathrm{l}$ chloride concentration and Succinylated Gelatin $40.0 \mathrm{~g} / \mathrm{l}$.

The PH can be calculated by using the Henderson-Hasselbalch equation $\mathrm{pH}=\boldsymbol{p K}+\boldsymbol{l o g}\left(\left[\mathrm{HCO}^{-}\right] /(\mathrm{PaCO} 2 \times 0.03)\right.$, But it does not quantify the abnormalities. Another approach was therefore introduced to eliminate the limitation above which is the Stewart approach. ${ }^{(29)}$ According to Stewart, the variables that contribute to the body $\mathrm{pH}$ are: the strong ion difference (SID, $\Sigma$ [strong cations] $-\Sigma$ [strong anions]), the albumin concentration, and the PCO2. ${ }^{(10)}$ From this approach we can clear that the SID is the main variable to determine the metabolic influences on the body $\mathrm{pH}$, so if normal saline solution or a saline based solution is infused, an increase in chloride concentration (one of the main anions) will result, leading to a decrease in the SID and hence acidosis (the so called hyperchloremic metabolic acidosis). ${ }^{(10)}$ This is met with Dileep et al. ${ }^{(21)}$, who in their Randomized, three-way crossover study, cleared an incidence of hyperchloremia in patients receiving $\mathrm{NaCl}$ containing solutions ( including: normal saline, Gelofusine and Voluven) with a direct relationship between the degree of hyperchloremia and the concentration of $\mathrm{NaCl}$ in the solutions used. Also in their study Base et al. ${ }^{(10)}$ reported a significant hyperchloremia in patients infused with saline-based colloid versus non in who received a colloid in a balanced electrolyte solution. On the other hand Awad et al reported a significant hyperchloremia after 6\% hydroxyethyl starch (Voluven) but not $4 \%$ succinylated gelatin (Gelofusine). ${ }^{(27)}$ Hyperchloremic metabolic acidosis has been considered a benign and self limiting condition over the last few years ${ }^{(30)}$ with unclear clinical impact, however recent published data suggest that there is some. ${ }^{(10)}$ Noritomi et.al, ${ }^{(31)}$ reported a complex metabolic acidosis in patients with severe sepsis or septic shock on ICU admission mainly due to hyperchloremia. Wilkes et al ${ }^{(32)}$ in their study reported improved organ perfusion in patients who received balanced solution compared to those who received saline-based one. Also Ondiveeran and Fox-Robichaud ${ }^{(33)}$ suggested that solution composition may have an impact on the immune response.

We can attribute the significant difference in the $\mathrm{BE}$ to the difference in the electrolyte component of each solution as mentioned above. In their study Boldt et al. ${ }^{(34)}$ reported a significant decrease in BE after the use of unbalanced colloid HES in contrast to balanced HES, also Base et al. ${ }^{(10)}$ reported the same finding. 
The difference in CVP between both groups can be explained by the longer duration of plasma expansion of Gelofusine than Ringer's acetate. On the other hand, the urine output (UOP) and despite the different compartmental distribution of both solutions showed no significant difference between the two groups. This is met with Dileep et al. ${ }^{(21)}$ who reported equal volume of UOP in healthy volunteers after loading with 1 liter of different solutions using $0.9 \%$ saline, $4 \%$ succinylated gelatin (Gelofusine) and 6\% hydroxy-ethyl starch (Voluven), they attributed this to the fact that the colloids shifted fluid from the extravascular into the intravascular space.

When comparing the safety parameters within the same group, the current study showed that; in group A (Ringer's acetate) platelet count has significantly decreased after operation $(226.9 \pm 25.8$ to $171.4 \pm 18.4 \mathrm{p}$-value $<0.001)$. This finding comes in line with Olmos et al. ${ }^{(35)}$ and Tülün Öztürk et al. ${ }^{(36)}$ when assessing the effectiveness of priming the extracorporeal circulation system with albumin - mannitol combined with Ultrafiltration, Olmos et al, used a control group in which the extracorporeal circulation was primed with Ringer's lactate $1500 \mathrm{~mL}$, they reported a decrease in platelet count in their control group. Also Tülün Öztürk et al in their study about the effect of acute normovolemic hemodilution (ANH) using colloids on the coagulation parameters, they used a control group in which the extracorporeal circulation was primed with Ringer's lactate and mannitol without ANH, they reported a statistically significant decrease in the platelet count within the control group when comparing the baseline reading to that one hour after discontinuation of $\mathrm{CPB}$. Moreover the literatures reported that, thrombocytopenia commonly occurs during cardiac surgery using an extracorporeal circulation due to hemodilution, sequestration and destruction by the non-endothelial surfaces. ${ }^{(37)}$

Regarding the prothrombin time and concentration within group A (Ringer's acetate) there were a significant difference when comparing the preoperative and postoperative values, the prothrombin time prolonged and concentration decreased. This comes in line with Tülün Öztürk et al. ${ }^{(36)}$ who reported a significant prolongation of prothrombin time in their control group. Also, in the current study, the INR showed a significant increase after operation (with $1.1 \pm 0.06$ preoperative vs. $1.2 \pm 0.04$ postoperative p-value 0.02 ). In their study Olmos et al. ${ }^{(35)}$ reported an increase in the INR in the control group but without intra-group analysis.

The hematological parameters within group A (Ringer's acetate) showed that hemoglobin decreased significantly (preoperative $12.7 \pm 0.94$, postoperative $10.7 \pm 0.61 \mathrm{p}$-value $<0.001$ ) and hematocrit, also decreased significantly (preoperative 37.9 \pm 2.9 , postoperative $32.3 \pm 1.8 \mathrm{p}$-value $<0.001$ ). In their study Olmos et al. ${ }^{(35)}$ reported - within their control group - a decrease in hemoglobin and hematocrit but without intra-group analysis. Also, Tülün Öztürk et al. ${ }^{(36)}$ reported a significant decrease in hemoglobin within their control group, when comparing the preoperative values to that one hour after discontinuation of $\mathrm{CPB}$.

The significant increase in postoperative serum potassium level among patients of group A can be attributed to the potassium content of the solution used.

The safety variables within group B (gelofusine group) showed the same changes occurred as in group A (Ringer's acetate) except that there was no significance regarding the potassium level postoperatively, and when comparing the postoperative values of both groups, we found that, there were; significant decrease in postoperative platelet count, significant prolongation in prothrombin time, significant decrease in postoperative prothrombin concentration and significant increase in INR in group B(gelofusine group) when compared to group A (Ringer's acetate). Also, there was a significant decrease in hemoglobin concentration and hematocrit in succinylated gelatin group. This is met with Schramko et al ${ }^{(38)}$ and Nielsen VG ${ }^{(39)}$ who reported that both gelatin and HES solutions decreased $\mathrm{Hb}$, Hct, and PC more than Ringer's acetate. Also in their study about the effect of intravenous fluids (including; albumin, gelofusine, Haemaccel and saline) on platelet function and hemostasis in elective hip surgery, Evans et al ${ }^{(40)}$ reported that there was a significant decrease of $\mathrm{Hb}$, Hct and platelet count when comparing pre and post and pre and last time points in all fluid groups with less fall in saline group. Despite disturbances of coagulation parameters, these disturbances did not cause detectable clinical changes; this is met with Schramko et al. ${ }^{(38)}$ No adverse events were recorded in our study.

\section{Conclusion:-}

In conclusion, the succinylated gelatin is more effective plasma expander and gets more hemodynamic stability than Ringer's acetate. However it has worse outcome regarding the acid base balance and coagulation parameters (Despite no detectable clinical changes). The safety regarding kidney and liver functions and serum electrolytes was comparable between the two groups. 
We recommend further studies about balanced Succinylated gelatin (e.g. ISOPLEX 4\% W/V SOLUTION FOR INFUSION) produced by Beacon Pharmaceuticals U.K. containing Na $145 \mathrm{mmol}$, K 4mmol, chloride 105mmol, magnesium $0.9 \mathrm{mmol}$ and lactate $25 \mathrm{mmol}$, with osmolority of $284 \mathrm{mosm} / \mathrm{l}$ and MW 30,000 Daltons.

\section{References:-}

1. De Leeuw PW, Dees A: Fluid homeostasis in chronic obstructive lung disease. Eur Respir J Suppl 2003, 46:33s-40s.

2. Chappell D, Jacob M, Hofmann-Kiefer K, et al: A rational approach to perioperative fluid management. Anesthesiology 2008, 109:723-740.

3. Holte K, Kehlet H: Fluid therapy and surgical outcomes in elective surgery: a need for reassessment in fasttrack surgery. J Am Coll Surg 2006, 202:971-989.

4. Brunkhorst FM, Engel C, Bloos F, et al: Intensive insulin therapy and pentastarch resuscitation in severe sepsis. N Engl J Med 2008, 358:125-139.

5. Hartog CS, Bauer M, Reinhart K: The efficacy and safety of colloid resuscitation in the critically ill. Anesth Analg 2011, 112:156-164.

6. Mitra S, Khandelwal P: Are all colloids same? How to select the right colloid? Indian J Anaesth 2009, 53: 592607.

7. Perel P, Roberts I: Colloids versus crystalloids for fluid resuscitation in critically ill patients. 2012, Cochrane Database Syst. Rev 6: CD000567.

8. Levi M, Jonge E: Clinical relevance of the effects of plasma expanders on coagulation. Semin Thromb Hemost 2007, 33: 810-815.

9. McIlroy DR, Kharasch ED: Acute intravascular volume expansion with rapidly administered crystalloid or colloid in the setting of moderate hypo-volemia. Anesth Analg 2003; 96:1572-1577.

10. Eva M. Base, Thomas Standl, Andrea Lassnigg, et al: Efficacy and Safety of Hydroxyethyl Starch 6\% 130/0.4 in a Balanced Electrolyte Solution (Volulyte) During Cardiac Surgery Journal of Cardiothoracic and Vascular Anesthesia, Vol. 25, No 3 (June), 2011: pp 407-414.

11. Gallandat Huet RC, Siemons AW, Baus D, et al. A novel hydroxyethyl starch (Voluven) for effective perioperative plasma volume substitution in cardiac surgery. Can J Anaesth 2000; 47: 1207-15

12. Verheij J, van Lingen A, Beishuizen A, et al. Cardiac response is greater for colloid than saline fluid loading after cardiac or vascular surgery. Intensive Care Med 2006; 32: 1030-8

13. T. Haas, A. Preinreich,E. Oswald, W. Pajk,J. Berger,et al: Effects of albumin 5\% and artificial colloids on clot formation in small infants Anaesthesia, 2007, 62, pages 1000-1007

14. Schramko AA, Kuitunen AH, Suojaranta-Ylinen RT, Niemi TT. Role of fibrinogen-, factor VIII- and XIIImediated clot propagation in gelatin haemodilution. An in vitro study using thromboelastometry. Acta Anaesthesiol Scand 2009; 53: 731-5

15. Boldt J, Knothe C, Zickmann B, Andres P, et al: Influence of different volume therapies on platelet function in patients undergoing cardiopulmonary bypass. Anesth Analg 1993; 76: 1185-90

16. Saxena N, Chauhan S, and Ramesh GS: A comparison of hetastarch, albumin and Ringer lactate for volume replacement in coronary artery bypass surgery. J Anaesth Clin Pharmacol 1997; 13:117-20

17. Perel P, Roberts I: Colloids versus crystalloids for fluid resuscitation in critically ill patients. Cochrane Database Syst. Rev 2007; 17: CD000567

18. Despotis G, Avidan MS, Hogue CW. Mechanisms and attenuation of hemostatic activation during extracorporeal circulation. Ann Thorac Surg 2001; 72: 1821-31

19. Wilkes MM, Navickis RJ, and Sibbald WJ: Albumin versus hydroxyethyl starch in cardiopulmonary bypass surgery: a meta-analysis for postoperative bleeding. Ann Thorac Surg 2001; 72: 527-33

20. Roberta J. Navickis, Gary R. Haynes, and Mahlon M. Wilkes: Effect of hydroxyethyl starch on bleeding after cardiopulmonary bypass: A meta-analysis of randomized trialsJ Thorac Cardiovasc Surg 2012;144:223-30

21. Dileep N. Lobo, DM, Zeno Stanga, Mark M. Aloysius, et al: Effect of volume loading with 1 liter intravenous infusions of $0.9 \%$ saline, $4 \%$ succinylated gelatine (Gelofusine) and $6 \%$ hydroxyethyl starch (Voluven) on blood volume and endocrine responses: A randomized, three-way crossover study in healthy volunteers Crit Care Med 2010; 38(2): 464-70.

22. Boldt J: The balanced concept of fluid resuscitation. Br J Anaesth 2007; 99:312-315

23. Lamke Lo, Liljedahl SO. Plasma volume changes after infusion of various plasma expanders. Resuscitation 1976; 5:93-102.

24. Dubniks M, Persson J, Grande PO. Plasma volume expansion of 5\% albumin, 4\% gelatin, $6 \%$ HES 130/0.4, and normal saline under increased microvascular permeability in the rat. Intensive Care Med 2007; 33: 293-9 
25. Marx G, Cobas Meyer M, Schuerholz T, et al. Hydroxyethyl starch and modified fluid gelatin maintain plasma volume in a porcine model of septic shock with capillary leakage. Intensive Care Med 2002; 28: 629-35

26. Persson J, Grande PO. Plasma volume expansion and transcapillary fluid exchange in skeletal muscle of albumin, dextran, gelatin, hydroxyethyl starch, and saline after trauma in the cat. Crit Care Med 2006; 34: 2456-62

27. S. Awad, S. Dharmavaram, C. S. Wearn, et al. Effects of an intraoperative infusion of $4 \%$ succinylated gelatine (Gelofusine) and 6\% hydroxyethyl starch (Voluven) on blood volume. British Journal of Anaesthesia 2012; 109(2): 168-76.

28. Wilkes NJ, Woolf RL, Powanda MC, et al: Hydroxyethyl starch in balanced electrolyte solution (Hextend) Pharmacokinetic and pharmacodynamic profiles in healthy volunteers. Anesth Analg 2002; 94:538-544

29. Claude G, Pascale N, Ve'ronique L, et al: Quantitative Analysis of Acid-Base Disorders in Patients with Chronic Respiratory Failure in Stable or Unstable Respiratory Condition. Respir Care 2010; 55(11):1453-1463

30. Scheingraber S, Rehm M, Sehmisch C, Finsterer U. Rapid saline infusion produces hyperchloremic acidosis in patients undergoing gynecologic surgery. Anesthesiology 1999; 90:1265-70.

31. Noritomi DT, Soriano FG, Kellum JA, et al: Metabolic acidosis in patients with severe sepsis and septic shock: A longitudinal quantitative study. Crit Care Med 2009; 37:2733-2739.

32. Wilkes NJ, Woolf R, Mutch M, et al: The effects of balanced versus saline-based hetastarch and crystalloid solutions on acid-base and electrolyte status and gastric mucosal perfusion in elderly surgical patients. Anesth Analg 2001; 93:811-816.

33. Ondiveeran HK, Fox-Robichaud AE: Pentastarch in a balanced solution reduces hepatic leukocyte recruitment in early sepsis. Microcirculation 2004; 11:679-687.

34. Boldt J, Mayer J, Brosch C, et al: Volume replacement with a balanced hydroxyethyl starch (HES) preparation in cardiac surgery patients. J Cardiothorac Vasc Anesth 2010; 24:399-407.

35. Olmos MR, Ballester JA, Arteta MT.et al: Effect of priming solution and Ultrafiltration on post-operative bleeding and blood transfusion in cardiac surgery. Randomized controlled trial Rev Esp. Anestesiol Reanim. 2015; 62(2):81-89.

36. Tülün Öztürk, İsmet Topçu, Barış Tuncer, et al: Coagulation Effects of Hydroxyethylstarch Versus Modified Fluid Gelatin When Used as Normovolemic Hemodilution Solutions during Cardiac Surgery. GKDA Derg2014, 20(3):141-148.

37. Linda SL, Liza JE, Kaplan JA. Coagulation Monitoring, In: KAPLAN'S CARDIAC ANESTHESIA: THE ECHO ERA, ${ }^{\text {th }}$ ed. Philadelphia: Saunders Elsevier, 2011:496-519.

38. Schramko A, Suojaranta-Ylinen R, Kuitunen A.et al. Hydroxyethylstarch and gelatin solutions impair blood coagulation after cardiac surgery: a prospective randomized trial Br J Anaesth 2010;104(6):691-7

39. Nielsen VG. Hemodilution modulates the time of onset and rate of fibrinolysis in human and rabbit plasma. $\mathbf{J}$ Heart Lung Transplant 2006; 25: 1344-52

40. Evans PA, Heptinstall S, Crowhurst EC, et al.Prospective double-blind randomized study of the effect of four intravenous fluids on platelet function and hemostasis in elective hip surgery. J Thromb Haemost 2003; 1: $2140-8$. 